\title{
A Sociologia Funcionalista de Florestan Fernandes, os Tupinambás e as Novas Guerras
}

\section{The Functionalist Sociology of Florestan Fernandes, the Tupinambas and the New Wars}

Rev. Bra. Est. Def. v. 3, n 1, jan./jun. 2016, p. 53-67

ISSN 2358-3932

ALBERTO MONTOYA PALACIOS JR.

O debate sobre as "novas guerras" nas Relações Internacionais (RI) trouxe questionamentos sobre a consistência dos recortes teóricos clássicos, notadamente centrados no Estado, para a análise dos conflitos armados internacionais do período pós-Guerra Fria. Em especial, aqueles envolvendo atores de natureza não estatal, tais como "organizações terroristas", grupos paramilitares, redes de máfia e narcotráfico, senhores da guerra e "grupos tribais", chamaram a atenção de analistas como Mary Kaldor (2004, 2008a, 2008b), Kalevi Holsti (1996, 2000, 2004), John Keegan (2006), Martin van Creveld (1991, 2004), Barry Buzan (2012), Mohamed Ayoob (1995), Herfried Münkler (2005) e Geoffrey Parker (2009). Para estes, ditos fenômenos impuseram a necessidade de o campo teórico das RI, que aborda a Segurança e os Conflitos Internacionais, ser renovado por intermédio do diálogo com outras Ciências Sociais, máxime a Sociologia e a Antropologia.

Seguindo tal sugestão de diálogo, e enfocando as experiências de guerra não estatal no contexto ameríndio, divisamos a análise da "Função social da guerra na sociedade Tupinambá”, elaborada pelo sociólogo brasileiro Florestan Fernandes como tese de doutoramento em Ciências Sociais (Sociologia) pela USP em 1951, publicada pela primeira vez em 1952. Apesar da distância cronológica desta obra para com o debate contemporâneo das RI, a análise de Florestan apresenta consistência analítica e pontos de reflexão sobre a Sociologia e a Antropologia da guerra que, conforme cremos, podem ajudar a responder interrogantes suscitadas pelo debate das novas guerras.

Nessa linha, duas questões suscitadas pelas "novas guerras" podem ser iluminadas pela sociologia funcionalista de Florestan Fernandes sobre os

Alberto Montoya Palacios Jr. - Doutorando em Relações Internacionais pelo Programa de Pós-Graduação San Tiago Dantas (UNESP/ UNICAMP/ PUC-SP). Professor da Escola Superior de Propaganda e Marketing de São Paulo (ESPM-Sp). E-mail: moontoya@gmail.com. 
tupinambás: primeiro, pode-se considerar como equivalentes, no plano analítico, a guerra de sociedades não estatais e as guerras estatais? Segundo, o fenômeno da guerra pode ser definido em sua essência como uma continuação da política, ou da economia, por exemplo? Para responder essas questões, dividimos nossa análise em três pontos principais: 1) a caracterização sociológica funcionalista da guerra; 2) a sociologia funcionalista de Florestan Fernandes e a abordagem clausewitziana da guerra: balanço de um diálogo; 3) a contribuição da sociologia funcionalista da guerra para o campo de estudo das RI.

\section{CARACTERIZAÇÃO SOCIOLÓGICA FUNCIONALISTA DA GUERRA}

O interesse primordial de Florestan Fernandes centrava-se nos índios tupinambás da costa brasileira quinhentista e seiscentista. Como eram reputados guerreiros e cujas fontes por ele compulsadas consignavam informações de que, para além de aguerridos, ditos nativos eram canibais, impôs-se ampliar seus estudos prévios de mestrado sobre a organização social dos tupinambás, para enfatizar especificamente os aspectos da guerra e do canibalismo em seu doutoramento. Antes disso, Fernandes publicou um artigo que pavimentava o caminho para a pesquisa, intitulado "Análise funcionalista da guerra: possibilidade de aplicação à sociedade Tupinambá. Um balanço crítico da contribuição dos cronistas” (Fernandes 2009), etapa intermediária para a sua tese sobre a "Função social da guerra na sociedade Tupinambá” (Fernandes 2006).

Conforme acreditava o sociólogo, o método funcionalista lhe forneceria vantagens para analisar a guerra por não ficar refém de recorrentes limitações das abordagens clássicas. De entrada, sentia que um etnocentrismo ocidental difundido impelia os analistas a definir a guerra seguindo "fórmulas civilizadas" e circunscritas às ideias e lógicas modernas de Estado e soberania; tal como definido por Bushnell em seu verbete sobre a guerra no Dictionary of Sociology, para quem a guerra é um tipo de conflito armado extensivo entre grupos humanos organizados, considerando-se a "si próprios como politicamente soberanos e eticamente habilitados para sustentar pela força seus direitos, que eles consideram bloqueados ou usurpados por seus oponentes armados" (Bushnell apud Fernandes 2009, 202-203).

De igual maneira, Fernandes se distanciou de outro funcionalista renomado, Bronislaw Malinowski, pelas ideias por este manifestadas em artigo sobre a guerra e a Antropologia em momento crítico - janeiro de 1941 -, durante a Segunda Guerra Mundial. Para Malinowski (1941), o conceito de guerra corresponderia apenas à "disputa armada entre duas unidades políticas independentes, por meio de força militarmente organizada, na 
prossecução de uma política (policy) tribal ou nacional”. Esta fórmula, todavia, soava por demais limitada para Fernandes.

Por fim, o sociólogo coincidiria mais com o demógrafo Corrado Gini na desistência da pretensão de explicar a guerra por meio de um princípio geral ou causa universal, tal como a política ou a economia. Interessava-lhe considerar a guerra no contexto social em que se manifesta, isto é, como ela "penetra as demais esferas da vida social e como é por elas influenciada", já que estes "são os dois problemas básicos da investigação sociológica" (Fernandes 2009, 206). Nesses termos, e dialogando com Georg Simmel, Fernandes considerará a guerra como uma forma de luta armada coletiva, que afeta e é afetada por outras esferas da vida social, emergindo como um mecanismo e um tipo de socialização que, no âmbito das relações entre grupos autônomos em guerra, culminaria em um status quo entre os agrupamentos armados - o reconhecimento de igualdades hostis.

No caso das sociedades ditas "primitivas" (não estatais), a guerra seria influenciada por um "terminus a quo subjetivo": a importância dela no sistema de relações intergrupais decorre de ela ser uma das poucas modalidades conhecidas de relações com os estranhos, os estrangeiros. A guerra assumiria a sua forma típica de uma relação social. Enquanto tal, necessita de normas e regras (por exemplo, o jus in bello), sem as quais os combates não poderiam ocorrer entre os beligerantes, reciprocamente iguais entre si (hostis). Ao revés, para o interior do grupo, o estado de guerra "exerceria nas relações domésticas, uma ação galvanizadora, que favorece a coesão interna, eliminando ou neutralizando as divergências sociais e grupais" (Fernandes 2006, 206).

Os efeitos socializadores da guerra são marcantes nas relações inter e intrassocietárias. No último caso, corresponderia, de um lado, à "solidariedade intragrupal', de outro, na organização das personalidades dos atores e à sua "belicosidade grupal", o desejo de guerrear, de vingar, matar, pilhar ou destruir os inimigos. A solidariedade intragrupal é uma forma de exaltação do Nós coletivo contra os outros, os de fora, os estrangeiros, os inimigos. Esse efeito não é automático e livre de distúrbios, pelo que possivelmente haverá manifestações inconformistas e frustrações sociais sobre os ideais coletivos de unidade frente aos "inimigos".

Para compreender esse recorte contextualizaremos o fenômeno social da guerra relacionando-os aos conceitos de fato social total e sistema de prestações totais (Lévi-Strauss 2008, 25). Em ambos os casos, o fenômeno é entendido pela maneira como afeta e é afetado pelas diferentes esferas do social. Em sua "Introdução à obra de Marcel Mauss", expoente funcionalista que usou com maestria esses conceitos, o antropólogo Lévi-Strauss depura que o fato social total, nesta corrente metodológica, abarcaria uma 
abordagem tridimensional dos fenômenos: faz coincidir uma dimensão sociológica, em seus aspectos sincrônicos; uma histórica ou diacrônica; e uma fisiopsicológica. A crença é a de que essa tríplice aproximação poderá realmente ocorrer somente nos indivíduos. Tal postura analítica seria profícua, pelo motivo de que o fato social total não implica apenas que "tudo o que é observado faça parte da observação, mas que o próprio observador, da mesma natureza que seu objeto, seja ele mesmo uma parte de sua observação" (Lévi-Strauss [1950] 2008, 25).

O conceito de fato social total aplicado ao âmbito das relações intersocietárias à mão armada, sobejamente a guerra tupinambá e de outros povos, seria uma espécie de prestação total de reciprocidades. O elemento fundante do sistema de prestação da dádiva é um trinômio de obrigações e expectativas de comportamento social ideal, melhor dito, de reciprocidade disposta em dar-receber-retribuir. Nessas relações de reciprocidade há doadores, donatários e uma "dádiva" que circula nas trocas entre os grupos. A troca e a circulação não é restrita apenas aos bens materiais ou de utilidade econômica, pois a dádiva pode assumir a forma de hospitalidade, cordialidade, serviços militares, mulheres, danças, festas, cativos de guerra, etc. Importa mais o valor simbólico, muitas vezes intrínseco ou imanente à dádiva, do que o valor econômico utilitário atribuído ao que é trocado; como é o caso do "Hau", elemento mágico imanente às dádivas dos trobiandenses e que impunha o imperativo ao objeto, chamado de taonga, de circular entre os contratantes. As pessoas presentes no contrato não seriam os indivíduos propriamente, mas pessoas de categoria moral e coletiva: clãs, famílias, tribos, por exemplo. A prestação total seria marcada pela manifestação difusa e ao mesmo tempo contundente do sistema de prestações, ficando a sua observância e cumprimento pelas partes entre a voluntariedade e a obrigação social (Mauss 2008, 191). O ponto que intrigava Mauss sobre o fenômeno da prestação total era a manifestação difusa e ao mesmo tempo contundente do sistema de prestações, ficando a sua observância e cumprimento pelas partes entre a voluntariedade e a obrigação social:

[…] essas prestações e contraprestações são feitas de uma forma voluntária, por presente, regalos, embora sejam, no fundo, rigorosamente obrigatórias, sob pena de guerra privada ou pública. Propusemo-nos chamar a tudo isso de sistema de prestações totais (Mauss 2008, 191, grifos no original).

Considerando a falência dos ajustes de comportamento ao sistema de prestações, negando-se a dar, a receber ou a retribuir as dádivas, a reciprocidade perturbada poderia fomentar antagonismos que redundassem em guerra privada, a ponto de cingir as parentelas e causar deslocamento 
geográfico de novos grupos sociais; ou em guerra pública, isto é, intersocietária entre os contratantes autônomos.

À parte da possibilidade de guerra por falência no sistema de prestações, como no caso do Kula, Mauss identificou nas festividades Potlatch, dos nativos do noroeste americano, um tom acentuadamente competitivo e intrínseco potencial violento àquela manifestação de prestação total. Nessas festividades, a própria rivalidade e possibilidade de guerra conformam uma modalidade de relação de reciprocidade intersocietária. Entre os sistemas mais "elementares" de reciprocidade, partindo da prestação total até os de tipo agonístico, como o Potlatch, haveria um gradiente de rivalidade e violência passível que variaria de acordo com as diferentes manifestações socioculturais das prestações totais, como nas Américas, África e Oceania (Mauss 2008, 194).

Observando esses fatores, Fernandes caracterizou social e sinteticamente o fenômeno da guerra, ajustando-o aos critérios de Corrado Gini, da seguinte forma:

A guerra constitui um estado das relações de conflito entre duas ou mais sociedades, provocado por comoções virtuais ou reais no sistema de relações intersocietárias, ou determinada pela ausência deste, em que os ideais coletivos de segurança, definidos ideologicamente, projetam-se nas personalidades dos indivíduos em ação, compelindo-os a se submeterem, a aceitarem ou a desejarem a contenda armada na qual se empenham direta ou indiretamente de modo organizado (Fernandes 2009, 209).

De maneira mais acurada, o sociólogo esclarece que sua definição se ajusta, logicamente, a quatro considerações adicionais:

1) a definição tanto pode ser aplicada à descrição do fenômeno em uma sociedade tribal, como a dos tupinambás, em que a guerra promovia a distensão das emoções coletivas sem, no entanto, lograr o estabelecimento de condições de consenso, quanto à descrição do fenômeno em sociedades do tipo ocidentais, em que isto é conseguido ao mesmo tempo que se fixa o poder relativo e recíproco de supremacia das sociedades beligerantes;

2) o caráter dinâmico do estado de guerra é ressaltado, sem referência, entretanto, à duração do mesmo (esta é um atributo indeterminável sinteticamente, pois varia de sociedade para sociedade, podendo ser reconhecida e qualificada de três modos distintos, como "permanente", "periódica" e "transitória”);

3) a definição abrange exclusivamente as relações intersocietárias “à mão armada”: os fenômenos societários de "luta armada" que resul- 
tam das relações de conflito entre segmentos sociais de uma mesma sociedade, designados de forma analógica por alguns autores como "guerra civil", "guerra de classes", etc., foram excluídos da caracterização; do mesmo modo, foram igualmente excluídas da caracterização todas as relações de conflito intersocietárias cujo reajustamento pode se processar, por meios espontâneos ou jurídicos, sem recurso ao emprego organizado da contenda armada, "com objetivos públicos ou quase públicos".

4) Por fim, não especifica quais os fatores sociais, como a "economia", a "religião", a "política", que determinam o estado de guerra; ao contrário, estabelece como critério básico de investigação a pesquisa da importância desses fatores, isoladamente e em conjunto, na motivação da guerra em sociedades particulares (isto é, em que medida e de que forma os desiquilíbrios operados no sistema de relações intersocietárias, ou a necessidade de criação deste sistema, vinculam-se aos fatores sociais enumerados) [ ...]

[...] pelo menos no estado atual do estudo do problema é muito mais conveniente considerar a guerra como parte de um sistema sociocultural, do que em termos de sua aproximação ou afastamento de categorias puras hipotéticas, elaboradas especulativamente (Fernandes 2009, 210-211).

Essas considerações adicionais coincidem para responder as questões levantadas sobre as "novas guerras". Impossibilitado de aplicar as fórmulas ocidentais modernas para análise da "guerra primitiva”, em especial de um povo já "desaparecido e exterminado", é possível afirmar que a sociologia de Fernandes ajuda-nos a analisar os conflitos contemporâneos vigentes, especialmente por não caracterizar a manifestação da guerra em referência à morfogênese e morfologia política do beligerante (não estatal ou estatal) e, talvez o mais importante, por não postular uma causa/ natureza universal para o fenômeno, tais como a política ou a economia.

Acrescentemos ainda que, na esteira clausewitziana, as possibilidades de desfecho para a guerra seriam dicotômicas: o grupo social vencido submete-se ao grupo social vencedor (guerra como instrumento de imposição da vontade política pela capitulação), ou procura subtrair-se à sua dependência ou evitar o extermínio, emigrando para outra área (geografia humana). Não obstante essa aparente dicotomia, Florestan percebeu com acuidade uma terceira alternativa, bastante difundida dentre "numerosas sociedades primitivas, inclusive a dos tupinambás, caracterizada pela obrigação da revindita”, ou guerra de vingança (Fernandes 2006, 20). 


\section{A SOCIOLOGIA FUNCIONALISTA DE FLORESTAN FERNANDES E A ABORDAGEM CLAUSEWITZIANA DA GUERRA}

De fato, Fernandes desfere pesadas críticas ao pensamento do militar prussiano, mas elas não implicam que se descarte como um todo aquele sistema de pensamento. Ao contrário, tratou de estabelecer pontes e diálogos, ainda que percorrendo caminho paralelo em sua pesquisa. Ademais, o debate com Clausewitz é bastante saliente no âmbito das "novas guerras", em especial nas obras de Keegan (2006), Munkler (2004) e Van Creveld (1991). Vejamos alguns aspectos deste diálogo.

Em primeiro lugar, distancia-se do prussiano pois, para Fernandes, não se poderia postular de antemão qual é a natureza da guerra (política, econômica, religiosa); é a análise sistemática de como a guerra se manifesta em cada contexto sociocultural, histórico e geográfico, que permitirá ao pesquisador chegar a tal inferência, pelo exame de suas funções sociais manifestas e latentes. A guerra é caracterizada como "um fenômeno social, que varia de sociedade para sociedade", e que pode ser acrescida do "seguinte corolário: os meios propriamente militares da guerra variam em conexão com as gradações sociais do fenômeno, de uma sociedade para outra" (Fernandes 2006, 134, grifos no original). É por via dessa caracterização que se entende a guerra tupinambá em sua especificidade - "a guerra na sociedade tupinambá não evoluiu no sentido de se realizar como um instrumento da política (ou, em outras palavras, como uma força de expansão do sistema organizatório tribal)" (Fernandes 2006, 134, grifos no original).

A guerra estava integrada às estruturas sociais de natureza mágico-religiosa que faziam a religião, e não a "política”, o "meio excelente de exacerbação e estado mais forte da consciência coletiva”, seja na relação da comunhão dos vivos entre si, seja na comunhão dos vivos para com os mortos e as demais entidades sobrenaturais que circunscrevem socialmente a sua manifestação. O mesmo valeria para as estratégias, táticas e armamentos utilizados, que deveriam ser explicados pelos seus ajustamentos aos valores mágico-religiosos, pois é neles, e "não no sistema 'militar' destes aborígenes, que está a explicação sociológica do 'nível militar' da guerra na sociedade tupinambá” (Fernandes 2006, 134). Em contraste, os clausewitzianos postulam a guerra como um "instrumento da política; ela traz necessariamente a marca dessa política; ela deve avaliar tudo à imagem da política”, ou seja, que a guerra é a política (Clausewitz 2003, 878).

Segundo, descarta que a guerra seja um "ato de violência destinado a forçar o adversário a submeter-se à nossa vontade” (Clausewitz 2003, 7), com o fito de impor ou gozar a paz em melhores condições, posto que o signi- 
ficado social de vitória e derrota militar variam culturalmente, nem sempre significando que a dominação ocorra na esfera do político, ainda que o significado da política varie culturalmente (Fernandes 2006, 427).

De acordo com Keegan (2006, 29-30, 33, 41), Clausewitz enxergaria nas formas de guerra tribal e primitiva, como a dos tupinambás, manifestações de violência que ele não classificaria como efetivamente guerra. Quiçá, por não divisar um horizonte político e militar próprios nas guerras não estatais, elas figuram em seu pensamento como uma subcategoria das guerras das nações civilizadas, mas que respondem à mesma função: "a guerra de uma comunidade - de nações inteiras e, particularmente, de nações civilizadas surge sempre de uma situação política e só resulta de um motivo político" (Clausewitz 2003, 26).

Igualmente, os grandes guerreiros tupinambás, os morubixadas, destituídos de qualquer poder vinculante sobre os demais guerreiros, não se enquadrariam à figura virtuosa do gênio guerreiro do militar responsável pelo duelo de vontades (Clausewitz 2003, 50). Por carecerem de desenvolvimento espiritual, os tupis não conheceriam a genuína guerra, pela razão que esta, quando verdadeira, é impregnada pelo espírito, que "impõe-se antecipadamente à vontade que guia e move toda a massa de forças”, quer sejam as materiais ou, mais fortemente, as morais (Clausewitz 2003, 184). Dessa defasagem espiritual e da lassidão no controle das forças materiais e morais da guerra primitiva, resulta que essas guerras sejam mais cruéis e destruidoras do que as praticadas pelas nações civilizadas (Clausewitz 2003, 8) parecer questionável do ponto de vista etnológico.

Terceiro, não havendo um corpo militar segmentado e à parte da sociedade civil, menos ainda generais entre os tupinambás, não faz sentido falar em submissão do estratégico ao político, ou do militar ao civil, já que condição de ser cidadão é a de ser guerreiro; não há caserna ou gabinetes (Lévi-Strauss 2014, 330-333; Clastres 2014, 242, 243, 251-257, 355; Melatti 2014, 155).

À parte dos pontos de distanciamento entre Fernandes e Clausewitz, há outros de diálogo. No geral, pode-se dizer que as suas discordâncias estão circunscritas à esfera da política. É que o sociólogo reconheceu, junto com a escola militarista prussiana, que "três leis gerais" poderiam se aplicar à caracterização da guerra, ainda que apenas nas esferas do estratégico e do tático (Fernandes 2006, 116, 124), posto que a função da guerra varia culturalmente, a saber:

a) no plano tático é aceito que o objetivo da guerra seja o de impor a vontade ao inimigo. No caso tupinambá, trata-se de garantir o sucesso da expedição de captura dos cativos e o seu regresso ao grupo local. Acontece que a situação tática não derivava de elementos políticos; o mais apropria- 
do seria analisar pelo prisma de uma espécie de dominação mágico-religiosa, mas, que por ser imanente e socialmente compartilhada pelo outro, vê-se debilitada a ênfase nos aspectos de projeção de poder político vinculatório por meio da guerra e da religião, restringindo-se a assertiva da imposição da vontade aos planos estratégico e tático;

b) toda a configuração das batalhas e combates pode ser caracterizada quanto às forças defensivas e ofensivas na guerra;

c) influem sobre a condução da guerra as qualidades físicas, intelectuais e morais dos homens (Fernandes 2006, 463).

Sobre a estratégia de guerra tupinambá, caso seja possível empregar esse termo, três elementos se impunham e influenciavam mutuamente: "a distância a ser percorrida, a duração da expedição e a composição do bando guerreiro". Sendo esses três os "problemas estratégicos" com os quais os líderes guerreiros tribais deveriam lidar (Fernandes 2006, 116). No tocante à tática, "os bandos guerreiros estavam organizados para os combates de curta duração: para o ataque de surpresa e a exploração dos seus efeitos na captura de adversários" (Fernandes 2006, 124). Vê-se, nessas esferas, Fernandes caracterizar as ações estratégicas e táticas de maneira próxima a Clausewitz, conforme admitido pelo sociólogo. Especialmente a surpresa nas guerras, importante para a tática tupinambá, é analisado pelo prussiano em capítulo dedicado e aproveitado por Fernandes (Clausewitz 2006, cap. IX, 209). Sobre os aspectos morais, Fernandes não nega que haja espaço para as paixões e comportamentos irracionais, mas a abordagem patológica não pode esgotar de antemão as tentativas de explicação positiva e científica do fenômeno.

Ao reconhecer, junto com Clausewitz, que certas leis gerais, ou proposições, parecem manifestar-se em todas as guerras, isso não significa que o sociólogo endosse os prognósticos estratégicos e táticos clausewitzianos. Por exemplo, a importância do elemento surpresa e as operações militares de atacar, capturar cativos e recuar rapidamente, analisadas por Clausewitz, mas conforme praticada pelos tupinambás, poderiam ser complementadas e atualizadas, a nosso ver, pelo referencial das táticas de guerrilha e da Estratégia Indireta (Hard 1982; Beaufre 1998; Saint-Pierre 2000), trazendo conceitos mais acurados do que as noções clausewitzianas de batalha decisiva, concentração das forças e diversão para o caso tupinambá.

Neste sentido, acreditamos ser possível o diálogo entre a sociologia funcionalista de Fernandes e o sistema teórico-filosófico de Clausewitz, desde que atentando para a sua incompatibilidade na esfera do político, e a sua convergência, ponderada e ajustada, na análise das esferas da estratégica e da tática nas guerras. 


\section{A CONTRIBUIÇÃO DA SOCIOLOGIA DA GUERRA DE FERNANDES PARA O CAMPO DE ESTUDO DAS RI}

Diversos aspectos da sociologia de Fernandes convidam a reflexões maiores do que seu escopo de pesquisa original sobre os tupinambás. $\mathrm{O}$ próprio autor reconhece e nos convida a isso nas notas finais de seu livro, sob o título de Contribuição geral à Teoria Sociológica da Guerra (Fernandes 2006, 435). Conforme cremos, seus estudos trazem significativas contribuições também para o campo de pesquisa das Relações Internacionais, complementando lacunas e interrogantes do debate suscitado pelas "novas guerras", tais como a caracterização do fenômeno da guerra como uma continuação da política e a relação desta com a morfogênese e a morfologia política das sociedades.

A interpretação fernandiana evidencia que, em certos contextos socioculturais, a lógica de que a guerra é um instrumento de imposição de vontade política para a consecução da paz, por intermédio do desarmamento do inimigo, seria inviável, pois, nesse caso, a paz, enquanto ausência de conflito gerado pela capitulação adversária, romperia a reciprocidade agonística entre as sociedades iguais, ainda que hostis (Fernandes 2006, 418). Destacar a guerra como uma forma de relação agonística e que possui efeitos socializadores é um ponto delicado, pois a função socializadora da guerra intervém, de fato, no "processo social indicado, mas o faz por recorrência, não como um fator condicionante (ou causal) imediato", por exemplo, inibindo as cisões dentro das parentelas (Fernandes 2006, 282).

A realização da guerra pressupõe uma socialização anterior a ela, pois os seus efeitos socializadores, operados etológica e eidologicamente na religião tribal, antes galvanizavam e ampliavam a solidariedade mínima necessária para a guerra do que a geravam (Fernandes 2006, 426). Essa é mais uma crítica direta de Fernandes ao "viés de diversos cronistas e defendido teoricamente por diversos autores”, segundo o qual a "união social interna está em relação direta com os perigos oferecidos por um meio humano externo hostil. Se isso fosse verdadeiro com referência à sociedade tupinambá, é presumível que não ocorressem fragmentações internas” (Fernandes 2006, 282). Disto, depura-se que não era a "guerra em si e por si que unificava as parentelas”. As incursões e excursões dos bandos guerreiros eram realizadas "pelos grupos das parentelas já solidárias entre si, a coesão tribal era um requisito para a guerra, em vez de ser um de seus efeitos" (Fernandes 2006, 282). Logo, os efeitos integrativos da guerra podem ser interpretados como, primariamente, oriundos da própria dinâmica da sociedade tribal (Fernandes 2006, 426). Tal consideração aproxima-se bastante de proposições no âmbito da sociologia da violência e da guerra de Sinisa 
Malesevic (2010) em sua crítica aos estudos de alguns analistas das novas guerras que defendem que a guerra é o que gera os efeitos socializadores, por intermédio de um inimigo externo, nas sociedades.

A dinâmica se desdobrava nos rituais de aprisionamento do cativo e de sua integração à comunidade dos captores. Acontece que esses ritos não implicavam o fim do estado de guerra, mas a sua continuação sob forma distinta, porque era como o "inimigo escravo realizaria o seu destino de vítima e o fazia, dentro de suas possibilidades, de modo agonístico, vivendo o sacrifício como uma situação de luta armada", compartilhando o ethos do agressor e transformando-o no seu instrumento executor de morte nobilitária (Fernandes 2006, 317). A importância sociológica desse resultado, advém da "congruência da referida noção de estado de guerra, que se incorporava à consciência social dos aborígenes, com o conceito de guerra adotado neste trabalho e com as implicações teóricas do mesmo" (Fernandes 2006, 317-318). Em suma, "a guerra tinha por função, nessa sociedade, preservar o equilíbrio social e o padrão correspondente de solidariedade social” (Fernandes 2006, 422). Veja-se que as condições e fatores estruturais da vida social tupinambá, como a política e a economia, seriam insuficientes para gerar a convivência e solidariedade social necessárias para a guerra, estas seriam fornecidas pelos valores mágico-religiosos (Fernandes 2006, 433).

Outra questão, para a qual acreditava serem necessárias mais análises, refere-se à integração e funcionamento da guerra em sociedades nas quais os guerreiros não constituem uma associação separada e cujas funções militares são indiferenciadas, ou naquelas onde a separação entre a comunidade dos guerreiros e as diferenciações das funções militares assumissem feições peculiares e tênues (Fernandes 2006, 464); remetendo-nos, novamente, às vinculações entre a morfogênese política e a ocorrência de guerras nas sociedades primitivas, históricas ou contemporâneas. Com efeito, tal abordagem serve de ponte para o tema "Os Estados Falidos e as novas guerras”, pois aí se enfatiza os aspectos de organização política e a reivindicação de monopólio do uso da força física num território, por atores estatais frente a grupos não estatais, tema capitais das análises de van Creveld (1991, 2004), John Keegan (2006) e Herfried Munkler (2004).

\section{CONSIDERAÇÕES FINAIS}

Apesar do fôlego e qualidade argumentativa de Florestan Fernandes, sendo considerado por Carlos Fausto, ainda hoje, como o melhor estudo comparativo e sistemático dos cronistas sobre os tupinambás, o sociólogo teria deslindado para uma interpretação que não corresponderia com 
acuidade a interligação entre a guerra e a religião tupi. A "tupinologia" do perspectivismo ameríndio, de Eduardo Viveiros de Castro e Manuela Carneiro da Cunha (2009), que receberam contribuições de Pierre e, sobretudo, de Hélene Clastres e Lévi-Strauss, expuseram pontos sensíveis da análise de Fernandes. Ainda que utilizados de maneira meticulosa e ponderada, aos instrumentos de análise funcionalista de Fernandes foram somados, de outra parte, uma audácia confessa na interpretação dos cronistas sobre os ritos de execução e o discurso entre o matador e a vítima. Esta audácia levou-o a identificar uma religião de culto aos espíritos dos antepassados, responsáveis pelo imperativo da guerra, de consistência etnográfica discutível. Justamente, este é o ponto nevrálgico daquela cosmologia, sua relação com os mortos, que, se pudesse ser observada mais de perto por Fernandes, talvez identificaria ali o baixo rendimento e quase nulidade da ancestralidade e seus cultos na religião dos tupis. Seu apego ao método funcionalista poderia tê-lo levado a importar a explicação da religião de ancestralidade, mais difundida na África ou Polinésia, para a guerra tupi. Conforme defenderá Viveiros de Castro e Carneiro da Cunha, revisitando os arawetés contemporâneos, o fenômeno da guerra não é plenamente captado na cosmologia tupi pela remissão ao culto dos antepassados e pelas abordagens etológica e eidológica; antes, seria o caso de analisar a guerra de maneira ontológica.

Apesar dessas críticas, cremos que a obra de Fernandes merece destaque entre os estudos de Sociologia da Guerra. A abordagem da guerra enquanto relação de reciprocidade e o diálogo com o pensamento Clausewitz são particularmente profícuos para o debate das "novas guerras", ampliando as ferramentas analíticas do campo teórico das RI e complementando as pesquisas de autores como John Keegan, Herfried Munkler e Martin van Creveld.

\section{REFERÊNCIAS}

Ayoob, M. 1995. The Third World Security Predicament: State Making, Regional Conflict, and the International System. Bouder and London: Lynne Rienner.

Beaufre, A. 1998. Introdução à Estratégia. Rio de Janeiro: Bibliex.

Buzan, B., Hansen, L. 2012. A evolução dos Estudos de Segurança Internacional. São Paulo: Editora UNESP.

Clausewitz, C. V. 2003. Da Guerra. 2. ed. São Paulo: Martins Fontes.

Clastres, P. 2014. Arqueologia da Violência. 3. ed. São Paulo: Cosac Naify. 
Creveld, M. V. 2004. Ascensão e declínio do Estado. São Paulo: Martins Fontes. 1991. Transformation of War. New York: The Free Press.

Cunha, M. C. da; Viveiros de Castro, E. 2009. Vingança e temporalidade. In: Cunha, M. C. da. Cultura com aspas e outros ensaios. São Paulo: Cosac Naify.

Fausto, C. 2014. Os índios antes do Brasil. 4. reimpr. Rio de Janeiro: Zahar. [2001] 2014. Inimigos Fiéis: História, Guerra e Xamanismo na Amazônia. 1. ed. 1. reimpr. São Paulo: Edusp.

Fernandes, F. [1949] 2009. Análise funcionalista da guerra: possibilidade de aplicação à sociedade Tupinambá. Um balanço crítico da contribuição dos cronistas. In: . [1958]. A investigação etnológica no Brasil e outros ensaios. Apresentação de Edgard Assis Carvalho. 2. ed. rev. São Paulo: Global.

- [1951] 2006. A função social da guerra na sociedade tupinambá. Prefácio de Roque de Barros Laraia. 3. ed. São Paulo: Globo.

Hart, L. B. H. 1982. As Grandes Guerras da História. 3. ed. São Paulo: Ibrasa.

Holsti, K. 2000. Peace and War: Armed Conflicts and International Order 1648-1989. Cambridge: Cambridge University Press.

1996. The state, war, and the State of War. Cambridge: Cambridge University Press.

. 2004. Taming the sovereigns: institutional change in international politics. Cambridge: Cambrigde University Press.

Kaldor, M. 2006. New \& Old Wars: Organized violence in a global era. Cambridge: Polity Press.

. 2008a. Human Security. Cambridge: Polity Press.

. 2008b. Global Civil Society: an answer to war. Cambrige: Polity Press.

Keegan, J. 2006. Uma História da Guerra. São Paulo: Companhia de Bolso.

Lévi-Strauss, C. [1950] (2003). Introdução à obra de Marcell Mauss. In: Mauss, M. 2008. Sociologia e Antropologia. 3. reimpr. São Paulo: Cosac Naify. 2014. Tristes Trópicos. 12. reimpr. São Paulo: Companhia das Letras. 
Malesevic, S. 2010. The Sociology of War and Violence. Cambridge: Cambridge University Press.

Malinowski, B. 1941. An Anthropological Analysis of War . American Journal of Sociology, v. 46, n. 4, jan., p. 521-55.

Mauss, M. 2008. Ensaio sobre a Dávida. In: Sociologia e Antropologia. 3. reimpr. São Paulo: Cosac Naify.

Melatti, J. C. 2014. Índios do Brasil. 9. ed. 1. reimpr. São Paulo: Editora da Universidade de São Paulo.

Münkler, H. 2005. Viejas y nuevas guerras: asimetría y privatizacion de la violêencia. Madrid: Siglo XXI.

Parker, G. 2009. The Cambrigde Ilustrated History of Warfare. Cambridge: Cambridge University Press.

Saint-Pierre, A. de. [1713-28]. 2003. Projeto para tornar perpétua a paz na Europa. Prefácio de Ricardo Seintefus. Tradução de Sérgio Duarte. 1. ed. Brasília/São Paulo: Editora da Universidade de Brasília, Instituto de Pesquisa de Relações Internacionais/Imprensa Oficial do Estado de São Paulo.

Viveiros de Castro, E. 2014. A inconstância da alma selvagem. 5. ed. 1. reimpr. São Paulo: Cosac Naify. 


\section{A SOCIOLOGIA FUNCIONALISTA DE FLORESTAN FERNANDES, OS TUPINAMBÁS E AS NOVAS GUERRAS}

\section{RESUMO}

Esta pesquisa resgata a sociologia funcionalista de Florestan Fernandes, elaborada para análise da "função social da guerra na sociedade Tupinambá". Enfatizamos os aspectos teórico-conceituais daquela obra que contribuam para a pesquisa das "novas guerras" nas Relações Internacionais contemporâneas.

Keywords: Sociologia funcionalista; Florestan Fernandes; guerra tupinambá; novas guerras

\section{ABSTRACT}

This research revisits the functionalist sociology of Florestan Fernandes, formulated for the analysis of the "social function of the tupinambá warfare". We hallmarked the theoretical and conceptual aspects of such work that contributes on the subject of the new wars on the Contemporary International Relations.

Keywords: Functionalist Sociology; Florestan Fernandes; Tupinamba Wars; New Wars. 